\title{
Drug utilization study in ophthalmology department at a tertiary care hospital
}

\author{
Pritpal Singh Ahluwalia1, Mirza Shiraz Baig ${ }^{1 *}$, Amarnath Awargaonkar², Varsha Nandekar $^{2}$
}

\begin{abstract}
${ }^{1}$ Department of Pharmacology, ${ }^{2}$ Department of Ophthalmology, Government Medical College, Aurangabad,
\end{abstract} Maharashtra, India

Received: 02 February 2021

Revised: 06 March 2021

Accepted: 08 March 2021

*Correspondence:

Dr. Mirza Shiraz Baig,

Email: shirazdoctor@yahoo.com

Copyright: (C) the author(s), publisher and licensee Medip Academy. This is an open-access article distributed under the terms of the Creative Commons Attribution Non-Commercial License, which permits unrestricted non-commercial use, distribution, and reproduction in any medium, provided the original work is properly cited.

\begin{abstract}
Background: Drug utilisation studies in present clinical practice have played significant role to promote rational drug use in the current health care system. The aim of present study was to analyse the prescribing pattern of drugs for various ocular conditions in Ophthalmology Department of Government Medical College and Hospital, Aurangabad, Maharashtra, India.

Methods: Study was prospective, observational open label and descriptive clinical study which included 100 patients in OPD and IPD during November 2018 to February 2019 fulfilling inclusion criteria.

Results: Out of the 100 study subjects, $56 \%$ were males and $46 \%$ were females, with the maximum number of patients falling in the age group 61-80 years. 38.26\% patients received antibiotics as most prescribed drug while $69 \%$ patients received analgesics and $47 \%$ anti-inflammatory. Among the antibiotics prescribed, fluoroquinolones were the most prescribed antimicrobial class. WHO prescribing indicators as analysed from the data collected were: average number of drugs per prescriptions was 3.79. Percentage of medicines prescribed by branded name- $33.79 \%$ and generic were $66.21 \% .54 \%$ of the total drugs prescribed were from the National List of Essential Medicines 2017.

Conclusions: Ocular ailments and conditions are frequently associated with high levels of utilization of drugs for their treatment. Thus, analysis of utilization of these drugs becomes very essential. In the present study, the drugs prescribed at our tertiary care hospital were found rational.
\end{abstract}

Keywords: Drug utilisation, Ophthalmic, Tertiary care hospital

\section{INTRODUCTION}

Drug utilisation research has been defined as the marketing, distribution, prescription, and drug use in the community by World Health Organisation (WHO). Special emphasis should be laid on the resulting medical, social, and economic consequences through research. ${ }^{1-3}$

Major bulk of the medicines are being prepared, dispensed or sold inappropriately and significant fraction of patients also fail to take them correctly according to World Health Organization (WHO). In recent years, the drug utilization studies has gained significant importance owing to increase in the prevalence of inappropriate drug use due to irrational prescribing, dispensing, and medication administration. Hence, a periodic auditing of drug utilization pattern has become indispensable to promote rational prescribing of drugs. ${ }^{4,5}$

The efficacy and safety of medicine utilized in ophthalmology is usually confounded by the accuracy of dose administration of the ophthalmic preparation by the patients which successively depends on proper education by the physician, a rational prescription and proper comprehension of the information provided to the patient, besides many other factors. ${ }^{6}$ 
Misuse of drugs is rather common occurrence amongst the developing nations as ours owing to irrationalities in prescribing, dispensing and administration of medications. $^{7}$

In the recent past, flooding of newer therapeutic agents and the tendency amongst physicians to prescribe these drugs more often has a growing concern. ${ }^{8}$

Recently, many drug developments and introduction of new ocular therapeutic agents have been additions to the field of ophthalmology. ${ }^{9},{ }^{10}$ Antibiotics are widely used for various ophthalmic diseases. Increasing trends of resistance to different class of antibiotics often used in ocular therapeutics have been documented. ${ }^{11-13}$

Consequently, indiscriminate and injudicious use of topical antibiotics and nonsteroidal anti-inflammatory drugs may give rise to histological and structural changes in conjunctiva. ${ }^{14,15}$

In order to improve therapeutic efficacy, curtail adverse effects, and delay the development of resistance, there is a serious need for periodic evaluation of trends in drug utilization. ${ }^{16}$

Present study evaluated drug utilization and prescribing practices of ophthalmologists with emphasis on antimicrobial utilization in a tertiary care teaching hospital in Aurangabad.

The aim of present study was to analyse drug prescribing pattern in a tertiary care Government Medical College Hospital, Aurangabad, Maharashtra, India.

\section{Aims and objectives}

Aims and objectives of the study were to study drug utilization pattern in ophthalmology in tertiary care hospital and to analyse the prescriptions as per WHO indicators.

\section{METHODS}

This was a cross sectional, prospective observational study carried out in Department of Ophthalmology, Government Medical College Aurangabad, (Maharashtra).100 patients attending Ophthalmology department OPD and IPD during November 2018 to February 2019 were studied.

\section{Inclusion criteria}

Patients of both sex with ophthalmic diseases and those willing to participate in the study were included in the study.

\section{Exclusion criteria}

Patients on additional drug treatment for ophthalmic complications or comorbid conditions and those who were not willing to give informed consent were excluded from the study.

Patients who came to ophthalmic OPD/IPD for consultation and fulfilled the eligibility criteria and giving a written informed consent were enrolled in the study. Details of prescribing were recorded from case record forms of OPD and IPD of ophthalmology department. All drugs prescribed was noted including drug name generic/trade, dose, route, dosage form, frequency of administration, indications for prescription and duration of therapy. The parameters studied were as below

Demographic characteristics of patients included- age distribution, gender distribution, age wise gender distribution.

Drug utilization pattern analysed average of route of administration of drugs, average number of drugs prescribed in the study population, number of individual class of drugs prescribed in the study population, analysis of combination of classes, analysis of individual class/drug, analysis of drugs used as monotherapy and combination therapy, and percentage of drugs prescribed by generic name.

Prescription analysis using WHO drug use indicators included the average number of drugs per encounter, percentage of drugs prescribed by generic name, percentage of encounters with an antibiotic prescribed, and percentage of encounters with an injection prescribed.

\section{Statistical analysis}

The data was analysed using descriptive statistics in SPSS software version 21. The Demographic and continuous variables data was expressed as mean \pm SD (standard deviation). The categorical data was expressed as a percentage.

\section{RESULTS}

A total of $n=100$ patients aged 1-80 years and above who had visited ophthalmology OPD/IPD for the treatment of various ocular conditions from November 2018 to February 2019 were enrolled.

Table 1: Age distribution.

\begin{tabular}{|lll|}
\hline Age (in years) & No. of patients & Percentage \\
\hline $\mathbf{0 - 1 0}$ & 5 & 5.00 \\
\hline $\mathbf{1 1 - 2 0}$ & 3 & 3.00 \\
\hline $\mathbf{2 1 - 4 0}$ & 5 & 5.00 \\
\hline $\mathbf{4 1 - 6 0}$ & 38 & 38.00 \\
\hline $\mathbf{6 1 - 8 0}$ & 49 & 49.00 \\
\hline Mean $=79.22$ & & \\
\hline
\end{tabular}

In this study, out of 100 patients, $56 \%$ patients were males, and $44 \%$ patients were females. 
Table 2: Gender distribution.

\begin{tabular}{|lll|}
\hline Gender & No. of patients & Percentage \\
\hline Female & 44 & 44.00 \\
\hline Male & 56 & 56.00 \\
\hline
\end{tabular}

Table 3: Age wise gender distribution.

\begin{tabular}{|llll|}
\hline \multirow{2}{*}{ Age (in years) } & \multicolumn{2}{l|}{ No. of patients } \\
& Total & Male & Female \\
\hline $\mathbf{1 - 2 0}$ & 8 & 3 & 5 \\
\hline $\mathbf{2 1 - 4 0}$ & 5 & 4 & 1 \\
\hline $\mathbf{4 1 - 6 0}$ & 38 & 13 & 25 \\
\hline $\mathbf{6 1 - 8 0}$ & 49 & 36 & 13 \\
\hline Total =100 & & & \\
\hline
\end{tabular}

The relative distribution of age wise gender categories was, in age group from 61 to 80 , out of 49 patients, 36 were males and 13 were females. In age group from 41 to 60 , out of 38 patients 13 were males and 25 were females. Majority patients in our study lie in the age group between $61-80$ years.

Table 4: Ophthalmic conditions.

\begin{tabular}{|lll|}
\hline Diagnosis & Frequency & Percentage \\
\hline Glaucoma & 3 & 3.00 \\
\hline Dacrocystitis & 3 & 3.00 \\
\hline $\begin{array}{l}\text { Conjunctival pathology } \\
\text { (cyst, granuloma, } \\
\text { inflammation) }\end{array}$ & 4 & 4.00 \\
\hline Pterygium & 7 & 7.00 \\
\hline Corneal & 7 & 7.00 \\
\hline Others & 16 & 16.00 \\
\hline Cataract & 60 & 60.00 \\
\hline
\end{tabular}

Out of 100 patients analysed, majority $(60 \%)$ were cataract patients either due to old age, trauma or other aetiology indicating most common eye disease prevalent in the set up.

Others include eye diseases due to uvea, or iris pathology and include cases of acute uveitis and iris prolapse and also include cases of viral herpes zoster ophthalmic infection (viral cases). Pterygium and corneal disease constitute around $7 \%$ each.

The conjunctival pathologies include conjunctival cyst, granuloma or cases of conjunctivitis and constitute around $4 \%$ of the cases followed by granuloma (3\%) and dacrocystitis $(3 \%)$.

Among 379 different classes of drugs, 145 (38.26\%) patients received antibiotics as most prescribed drug while $71(18.73 \%)$ patients received analgesics as second most prescribed drug. Corticosteroids and anti-glaucoma drugs were given to 11 and 14 patients constituting $2.90 \%$ and $3.69 \%$ respectively.
Table 5: Most prescribed drugs $(n=379)$.

\begin{tabular}{|lll|}
\hline Drugs & Frequency & Percentage \\
\hline Corticosteroids & 11 & 2.90 \\
\hline Anti-glaucoma & 14 & 3.69 \\
\hline Anti-inflammatory & 50 & 13.19 \\
\hline Analgesics & 71 & 18.73 \\
\hline Antibiotics & 145 & 38.26 \\
\hline Antacids & 88 & 23.22 \\
\hline
\end{tabular}

Table 6: Antibiotics prescription $(n=145)$.

\begin{tabular}{|lll|}
\hline Type of antibiotics drugs & Frequency & Percentage \\
\hline Brand & 49 & 33.79 \\
\hline Generic & 96 & 66.21 \\
\hline
\end{tabular}

The number of patients prescribed branded antibiotics were $49 \%$ and generic antibiotics were $96 \%$.

Table 7: Descriptive analysis of class of antibiotic drug therapy in the study population $(n=99)$.

\begin{tabular}{|lll|}
\hline Class of drug therapy & Frequency & Percentage \\
\hline Monotherapy & 45 & 45.45 \\
\hline Combination & 46 & 46.46 \\
\hline Fixed drug combination & 8 & 8.08 \\
\hline
\end{tabular}

Out of 99 antibiotics, 45 patients $(45.45 \%)$ patients were prescribed monotherapy, and 46 patients $(46.46 \%)$ were given antibiotics in combination with 8 patients $(8.08 \%)$ prescribed fixed dose combination therapy.

Fluoroquinolones were the most prescribed antimicrobial class. Fluoroquinolones accounted for the major of the total prescribed antimicrobials, of which ciprofloxacin was the most frequently prescribed (76 patients out of 100) in the tablet (oral) form among the fluoroquinolones, followed by moxifloxacin.

Table 8: Descriptive analysis of antibiotics prescribed and total drugs prescribed in study population $(n=99)$.

\begin{tabular}{|lllll|}
\hline Parameter & Mean \pm SD & Median & Min. & Max. \\
\hline $\begin{array}{l}\text { Antibiotics } \\
\text { prescribed } \\
(\mathbf{n = 9 9 )}\end{array}$ & $1.46 \pm 0.56$ & 1.0 & 1.0 & 3.0 \\
\hline $\begin{array}{l}\text { Total drugs } \\
\text { prescribed } \\
(\mathbf{n = 1 0 0})\end{array}$ & $3.79 \pm 0.94$ & 4.0 & 1.0 & 7.0 \\
\hline
\end{tabular}

There were total 379 drugs prescribed from different classes. $27.82 \%$ of the total drugs prescribed were from the National List of Essential Medicines 2017.

In the corticosteroids, dexamethasone (7) was more commonly used corticosteroids than methylprednisolone (3) or prednisolone. For the treatment of glaucoma, timolol (9) was being used alone or in combination with 
cyclopentolate (3) and also a fixed dose combination of brinzolamide and brimonidine (2) was prescribed.

In the anti-inflammatory group, diclofenac was given in 32 patients with nepafenac in 10 patients, flurbiprofen in patients and diclofenac and nepafenac in 2 patients amongst 100 patients whereas in the analgesics, ibuprofen alone (most common), combi flam (ibuprofen + paracetamol), and nepafenac were prescribed to the patients (Table 9).

Amongst monotherapy, ciprofloxacin was most prescribed antibiotic followed by gatifloxacin and cefotaxime. Amoxicillin clavulanate was the most common prescribed FDC and combination of gatifloxacin and ciprofloxacin was the most used in combination therapy (Table 10).

Table 9: Descriptive analysis of names of prescribed drugs under various categories $(\mathbf{n}=100)$.

\begin{tabular}{|c|c|c|c|}
\hline Drug class & Drug name & & Number \\
\hline \multirow{3}{*}{ Corticosteroids } & Dexamethasone & 7 & \multirow{3}{*}{11} \\
\hline & Methylprednisolone & 3 & \\
\hline & Prednisolone acetate & 1 & \\
\hline \multirow{3}{*}{ Anti-glaucoma } & Timolol alone & 9 & \multirow{3}{*}{14} \\
\hline & Timolol and cyclopentolate both & 3 & \\
\hline & Brinzolamide + brimonidine & 2 & \\
\hline \multirow{4}{*}{ Anti-inflammatory } & Diclofenac & 32 & \multirow{4}{*}{50} \\
\hline & Nepafenac & 10 & \\
\hline & Both diclofenac and nepafenac & 2 & \\
\hline & Flurbiprofen & 6 & \\
\hline \multirow{3}{*}{ Analgesics } & Combiflam (ibuprofen + paracetamol) & 1 & \multirow{3}{*}{71} \\
\hline & Nepafenac & 10 & \\
\hline & Ibuprofen & 60 & \\
\hline
\end{tabular}

Table 10: List of antibiotics and their percentage wise distribution as in monotherapy, combination and FDC.

\begin{tabular}{|c|c|c|}
\hline Antibiotics & Drug name & Percentage \\
\hline \multirow{10}{*}{ Combination (46) } & 1. Tobramycin, chloramphenicol & 1 \\
\hline & 2. Gentamycin, cefotaxime & 3 \\
\hline & 3. Norfloxacin, cefotaxime & 3 \\
\hline & 4. Cefotaxime, gentamycin & 2 \\
\hline & 5. Cefotaxime, gentamycin, gatifloxacin & 3 \\
\hline & 6. Ciprfloxacin, moxifloxacin & 7 \\
\hline & 7. Amoxicillin, ciprofloxacin, gatifloxacin & 2 \\
\hline & 8. Gatifloxacin, ciprofloxacin & 19 \\
\hline & 9. Ciprofloxacin, ofloxacin & 3 \\
\hline & 10. Moxifloxacin, ciprofloxacin & 3 \\
\hline \multirow{4}{*}{ Fixed drug combination (8) } & 1. Amoxicillin clavulanate & 5 \\
\hline & 2. Brinzolamide + brimonidine & 1 \\
\hline & 3. Combiflam (paracetamol+ ibuprofen & 1 \\
\hline & 4. Moxiview-D (moxifloxacin + dexamethasone) & 1 \\
\hline \multirow{5}{*}{ Monotherapy (45) } & 1. Gatifloxacin & 6 \\
\hline & 2. Ciprofloxacin & 32 \\
\hline & 3. Moxifloxacin & 1 \\
\hline & 4. Neomycin & 2 \\
\hline & 5. Cefotaxime & 4 \\
\hline
\end{tabular}

\section{Percentage of oral and i.v. drugs $(n=379)$}

$54.09 \%$ of total drugs were given orally while $24.80 \%$ were given in eye drop dosage form, while $19.79 \%$ of total drugs were given in intravenous form and $5 \%$ in the form of ointment.

\section{Average number of drugs prescribed}

The average number of drugs prescribed per prescription in our study population was 4 with a standard deviation of $0.94(4 \pm 0.94)$. 


\section{Prescribing indicators evaluated as per WHO}

Average number of drugs per encounter (C)

$\mathrm{C}=\mathrm{B} / \mathrm{A}$ where $\mathrm{B}$ is total number of different drug products prescribed $\mathrm{A}$ is the number of encounters surveyed $\mathrm{C}=379 / 100=3.79$

\section{Percentage of drugs prescribed by generic name (E)}

$\mathrm{E}=\mathrm{D} / \mathrm{B} \times 100$ where $\mathrm{D}$ is the number of drugs prescribed by generic name and $B$ is the total number of drugs prescribed

\section{$\mathrm{E}=107 \times 100 / 379=28.23 \%$}

\section{Percentage of encounters with antibiotic/s prescribed $(G)$}

$\mathrm{G}=\mathrm{F} / \mathrm{A} \times 100$ where $\mathrm{F}$ is the number of patient encounters with one or more antibiotic/s prescribed $\mathrm{A}$ is the total number of encounters surveyed

$\mathrm{G}=1.46 \times 100 / 100=1.96 \%$.

Percentage of encounters with an injection prescribed $(K)$

$\mathrm{K}=\mathrm{J} / \mathrm{A} \times 100$, where $\mathrm{J}$ is the total number of patients who received 1 or more injections $(\mathrm{H}) \mathrm{A}$ is total number of encounters

$\mathrm{K}=19 \times 100 / 100=19 \%$.

\section{Core drug use indicators of current study}

Average consultation time $($ minimum $)=4.5$, average dispensing time $($ minimum $)=3.1$.

In our study $97.74 \%$ of antimicrobials were given topically as drops and ointment and only $54.09 \%$ were given orally, thus increasing chances of adverse effects. The frequency of drug use and dosage form has been noted for $98 \%$ and $94 \%$ of the drugs respectively. The duration of therapy has been recorded in $75 \%$ of the drugs prescribed in the study. The study-based prescriptions were almost complete in $75 \%$ cases.

\section{DISCUSSION}

The study was undertaken with an aim to analyse the prescription pattern in ophthalmology set up. In this study, prescriptions of a total of 100 patients aged 18 years and above were reviewed and analysed.

Data analysis of gender distribution in present study showed that there was a male predominance in this study. In the present study we found $56 \%$ prescriptions were of males and $44 \%$ were of females. This may be assigned due to differences in lifestyle, dietary habits, and stress.
In our study the most commonly encountered diseases were cataract $(60 \%)$, glaucoma (3\%), conjunctival pathology (4\%), pterygium (7\%) and others (16\%). whereas the study conducted by Jain et al encountered most common disease diagnosed as conjunctivitis (29\%) followed by blepharitis (14\%), ocular surface disorders $(12 \%)$, dry eye $(11 \%)$, glaucoma $(6.0 \%)$, corneal ulcer $(5.0 \%)$, meibomitis $(4.0 \%)$, iridocyclitis $(3.5 \%)$, diabetic retinopathy $(3.0 \%)$, foreign body $(3.0 \%)$, stye $(2.5 \%)$, dacrocystitis (2.0\%), and others (2.0\%). ${ }^{17}$ This difference in ocular disease prevalence can be due to different demographic and sanitation conditions and also indicates the high prevalence of cataract in our study population.

In the present study $97.74 \%$ of antimicrobials were given topically as drops and ointment and $54.09 \%$ were given orally. The frequency of drug use and dosage form thus was $98 \%$ (topically) and $94 \%$ (orally) respectively. The duration of therapy has been recorded in $75 \%$ of the drugs prescribed in the present study. In contrast, study conducted by Biswas et al showed the maximum number of drugs prescribed were in the form of eye drops $(76 \%)$, followed by tablets $(10.9 \%)$, ointments $(6.4 \%)$, syrups $(1 \%)$, capsules $(0.7 \%)$, lotions $(0.3 \%)$ and injections $(0.1 \%)$. No dosage form was recorded for $4.6 \%$ of the drugs prescribed and the frequency of administration was recorded for only $77.9 \%$ of the drugs prescribed in the study by Biswas et al. ${ }^{18}$

In our study, $36.82 \%$ of the total drugs prescribed were from the National List of Essential Medicines 2017 which is in contrast to the study conducted by Banerjee et al where it was $62 \% .^{19}$

In the present study, out of 99 antibiotics, 45 patients (45.45\%) patients were prescribed monotherapy, and 46 patients $(46.46 \%)$ were given antibiotics in combination with 8 patients $(8.08 \%)$ prescribed fixed dose combination therapy. The study conducted by Divya et al showed that, AMAs accounted for $52 \%$, out of which $47 \%$ were prescribed as single AMAs and 5\% were prescribed as FDC. ${ }^{20}$

Antimicrobials have been prescribed in $38.26 \%$ prescriptions, in the form of eye drops, eye ointment as well as orally. In our study mostly fluoroquinolones were used of which ciprofloxacin is most commonly used $(57.42 \%)$ which is comparable with the study conducted by Nehru et al $(62.5 \%)$ whereas gatifloxacin was the most commonly prescribed antibiotic $(42.42 \%)$ in the study conducted by Maniyar et al. ${ }^{21,22}$

In our study, drugs prescribed by generic names is $28.23 \%$, In contrast the study conducted by Isabella et al showed that the drugs prescribed by generic names was only $11.96 \%$ and brand name was $88.03 \%$.Thus, it is clearly evident from our study that still a smaller number of drugs were prescribed by generic drugs and pattern of prescribing by brand name was in trend in the set-up. ${ }^{23}$ But this is in contrast to findings noticed in study conducted by 
Priyanki et al where the percentage of drugs prescribed by generic name was $31.63 \%$ which was very close to our study. ${ }^{24}$

In our study the frequency of drug use and dosage form has been noted for $98 \%$ and $94 \%$ of the drugs respectively with the duration of therapy been recorded in $75 \%$ of the drugs prescribed in the study which is very similar to the study conducted by Akram et al where the routes of drug administration, dosage, frequency were mentioned in all prescriptions whereas dosage form was not mentioned in 4 $(2.27 \%)$ and duration of treatment was not mentioned in $23(13.06 \%)$ prescriptions. $^{25}$

Average number of drugs per prescription is an important index of the scope for review and educational intervention in prescribing practices. In this study the average number prescription was $4 \pm 0.94$ as compared to previously reported studies by Janaki et al which was $2.14 \%$ and stresses upon the need for review on a periodic basis and educational intervention in prescribing practices in clinical setups. $^{26}$

Our study has some limitations as well. The short period of 3 months for this study might be a limitation to the study conducted because a study conducted over a longer time period would have been more informative. Not taking into account the associated comorbidities of patients can be another limitation of this study.

The results obtained from this study may not be applicable to all the tertiary set ups as this study was conducted at a single centre only and it was difficult to generalise the findings owing to different geographic conditions, population distribution and other factors.

So, there is a need to conduct more multicentric studies. Also, few parameters pertaining to quality of treatment, quality of patient examination, quality of diagnosis are some domains which were not taken into consideration during the study.

Findings from this study can be used to overcome some deficiencies strategy wise in drug utilisation and baseline data obtained can be used in near future when any drug utilisation study in ophthalmology field is carried out.

\section{CONCLUSION}

Ocular ailments and conditions are frequently associated with high levels of utilization of drugs for their treatment. We conclude that in the present study, the drugs prescribed by ophthalmologist at our tertiary care hospital were found rational.

\section{ACKNOWLEDGEMENTS}

Authors would like to thank Department of Ophthalmology, Government Medical College,
Aurangabad, and Maharashtra, India for their support during study.

Funding: No funding sources

Conflict of interest: None declared

Ethical approval: The study was approved by the Institutional Ethics Committee of Government Medical College, Aurangabad, and Maharashtra, India

\section{REFERENCES}

1. World Health Organization (WHO) and International Network for Rational Use of Drugs, How to Investigate Drug Use in Health Facilities: Selected Drug Use indicators, WHO/DAP/93.1. WHO, Geneva: Switzerland; 1993.

2. World Health Organization (WHO) International Working Group for Drug Statistics Methodology, WHO Collaborating Centre for Drug Statistics Methodology, WHO Collaborating Centre for Drug Utilization Research and Clinical Pharmacological Services. Introduction to Drug Utilization Research. 2003. Available at: https://apps.who.int/iris/handle/10665/42627. Accessed on 3 December 2020.

3. World Health Organization, Introduction to Drug Utilization Research, WHO, Oslo, Norway, 2003.

4. Shalini S, Ravichandran V, Mohanty BK, Dhanraj SK, Saraswathi R. Drug utilization studies-an overview. Int J Pharm Sci Nanotechnol. 2010;3:803-10.

5. Prajwal P, Rai M, Kumar KS, Bhat US, Dsouza FV. Drug utilization pattern in ophthalmology department at a tertiary care hospital. Int Res $\mathbf{J}$ Pharm. 2013;4:205-10.

6. Tsai T, Robin AL, Smith III JP. An evaluation of how glaucoma patients use topical medications: a pilot study. Transact Am Ophthalmol Soc. 2007;105:29-35.

7. Slathia A, Gupta V, Nanda R, Mahajan P. Drug utilization pattern in ophthalmology: an observational and cross-sectional study. Int $\mathbf{J}$ Sci Stud. 2017;5(5):63-5.

8. Bhatt JH, Verma S, Bagde S, Sane RM, Shahani S. Drug utilization study in ophthalmology in OPD patients at a tertiary care teaching hospital. Int J Basic Clin Pharmacol. 2018;7:315-8.

9. Duggirala A, Joseph J, Sharma S, Nutheti R, Garg P, Das T. Activity of newer fluoroquinolones against gram-positive and gram-negative bacteria isolated from ocular infections: an in vitro comparison. Indian J Ophthalmol. 2007;55(1):15-9.

10. Leonardi A. Emerging drugs for ocular allergy. Exp Opin Emerg Drugs. 2005;10(3):505-20.

11. Afshari NA, Ma JJ, Duncan SM, Pineda R, Starr CE, DeCroos FC, et al. Trends in resistance to ciprofloxacin, cefazolin, and gentamicin in the treatment of bacterial keratitis. J Ocul Pharmacol Therap. 2008;24(2):217-23.

12. Asbell PA, Colby KA, Deng S, McDonnell P, Meisler DM, Raizman MB, et al. Ocular TRUST: nationwide 
antimicrobial susceptibility patterns in ocular isolates. Am J Ophthalmol. 2008;145(6):951-8.

13. Kowalski RP, Karenchak LM, Romanowski EG. Infectious disease: changing antibiotic susceptibility. Ophthalmol Clin North Am. 2003;16(1):1-9.

14. Sood AK, Gupta A, Dabral T. Indiscriminate use of topical antibiotics: a menace. Indian J Ophthalmol. 1999;47(2): 121.

15. Gaynes BI, R. Fiscella R. Topical nonsteroidal antiinflammatory drugs for ophthalmic use: a safety review. Drug Saf. 2002;25(4):233-50.

16. Krishnaswamy K, Kumar BD, Radhaiah G. A drug survey- precepts and practices. Eur J Clin Pharmacol. 1985;29(3):363-70.

17. Jain AK, Naimi S, Jain S. Assessment of antimicrobial prescribing pattern in the outpatient department of ophthalmology in a tertiary care hospital of western Uttar Pradesh, India. Nepal J Ophthalmol. 2018;10(20):130-8.

18. Biswas NR, Jindal S, Siddiquei MM, Maini R. Patterns of prescription and drug use in ophthalmology in a Tertiary Hospital in Delhi. Br J Clin Pharmacol. 2001;51:267-9.

19. Banerjee I, Bhadury T, Sengupta T, Roy D. Drug utilization study in ophthalmology out-patient department of a medical college in India. Ann Med Health Sci Res. 2014;4(4):667-70.

20. Divya K, Jayanthi CR, Nagaraju G. Drug utilization study in post cataract surgery patients in a tertiary care hospital. Int $\mathbf{J}$ Res Pharmacol Pharmacotherap. 2018;7(1):61-8.
21. Nehru M, Kohli K, Kapoor B, Sadhotra P, Chopra V, Sharma R. Drug utilization study in outpatient ophthalmology department of Government medical college. JK Sci. 2005;7:149-51.

22. Maniyar Y, Bhixavatimath P, Akkone V. A drug utilization study in the ophthalmology department of a Medical college, Karnataka, India. J Clin Diagn Res. 2011;5:82-4.

23. Topno I, Chennama B, Yugandhar B, Balakrishnan S. Antibiotic prescribing pattern in ophthalmology outpatient department in a tertiary care hospital. J Pharmacol Pharmacotherap. 2012;3(2):190-1.

24. Priyanki, Kumari K, Gari M, Pathak AK. A study of the current prescribing and drug utilization pattern in Ophthalmology Department of a tertiary care teaching hospital. Int J Basic Clin Pharmacol. 2019;8:497-501.

25. Akram MF, Shamsheer RP, Krishnan DG, Raju GJKP, Pawar TA. Drug prescribing pattern in ophthalmology out patient department of a medical college. Int Arch BioMed Clin Res. 2016;2(4):17-20.

26. Janaki DCH, Seethalakshmi S, Devaraj S. Drug utilization study in ophthalmology out patients in a tertiary care teaching hospital. Int $\mathbf{J}$ Basic Clin Pharmacol. 2020;9:1721-4.

Cite this article as: Ahluwalia PS, Baig MS, Awargaonkar A, Nandekar V. Drug utilization study in ophthalmology department at a tertiary care hospital. Int J Basic Clin Pharmacol 2021;10:396402. 